
\title{
BReserch S Suare \\ Experimental and Numerical Investigation of Effect of Cadmium Sorption by River Sediments on Longitudinal Dispersion
}

Mohsen Nasrabadi ( $\nabla$ nasrabadim@ut.ac.ir)

Arak University

Ali Mahdavi Mazdeh

Imam Khomeini International University

Mohammad Hossein Omid

Tehran University: University of Tehran

\section{Research Article}

Keywords: Cadmium, Sorption Ratio, River Bed Sediments, Longitudinal Dispersion

Posted Date: May 25th, 2021

DOl: https://doi.org/10.21203/rs.3.rs-507251/v1

License: (c) (i) This work is licensed under a Creative Commons Attribution 4.0 International License.

Read Full License 


\section{Longitudinal Dispersion}

3

4 The names of the authors:

5 1. Mohsen Nasrabadi*

6 Assistant Prof., Department of Water Science and Engineering Eng., Arak University. Karbala Sq., Arak, Iran, $7 \quad 31587-77871$.

8 E-mail: nasrabadim@ut.ac.ir, m-nasrabadi@araku.ac.ir

9 Telephone No.: +989105080029

10 ORCID: 0000-0001-8061-8836

\section{Ali Mahdavi Mazdeh}

13 Associate Prof., Department of Water Eng., Imam Khomeini International University. International University 14 Blvd., Qazvin, Iran, 34149-16818.

\section{Mohammad Hossein Omid}

17 Prof., Department of Irrigation \& Reclamation Eng., University of Tehran. Daneshkadeh St., Karaj, Iran, $31587-$ 1877871.

19 


\section{Abstract}

21 This paper concerns the cadmium sorptive effects by river bed sediments on longitudinal coefficient in an openchannel flow via experimental and numerical study. For this purpose, a circular flume was used with mean diameter of $1.6 \mathrm{~m}$ and a width of $0.2 \mathrm{~m}$. The adsorbing bed was considered as a thin layer of the sediment particles with mean diameter of $0.5 \mathrm{~mm}$ and three sediment concentrations of 3,12 , and $20 \mathrm{gr} / \mathrm{lit}$. To determine the sorption parameters of the sediments, some experiments were conducted with three cadmium concentrations of 150,460 , and $770 \mathrm{ppb}$. Then, the dispersion experiments were carried out with and without the bed sediments. To solve the advection-dispersion equation with considering the sorption term by river bed sediments, a numerical model was then developed. The longitudinal dispersion coefficients were estimated by comparing the experimental and numerical breakthrough curves. The results showed that, with increasing the sediment concentrations, the sediment sorption rate increased and the longitudinal dispersion coefficient decreased by about 38,36 and 33 percent, respectively, for cadmium concentrations of 150,460 and $770 \mathrm{ppb}$. In addition, by increasing the cadmium concentrations, the changes in the longitudinal dispersion coefficient are decreased. Furthermore, a relationship was developed using non-dimensional longitudinal dispersion as a function of the new parameter of sorption ratio. From a practical point of view, the results of this study demonstrated that, at the presence of sediment, the cadmium is longitudinally dispersed with more delay in comparison with no sediment at the river bed.

Keywords: Cadmium, Sorption Ratio, River Bed Sediments, Longitudinal Dispersion.

\section{Introduction}

Nowadays, most of the natural rivers are exposed to industrial wastewaters and heavy metal pollutions and the study of different factors affecting on the transport and the fate of these pollutants is important. On the other hand, the rivers typically carry the sediments via erosion and sedimentation processes. In addition, the river is usually contains the different sizes of sediments, most of them is very rich in organic matter, and therefore has a strong potential to adsorb chemical pollutants in a sorbate form ( $\mathrm{Ng} 2006 \mathrm{a})$. As a result, the presence of these sedimentary loads in the rivers, due to the high potential of metal ions to adsorb by sediment particles, may play an important role in the transport and fate of heavy metal pollutants. In this regards, many studies have demonstrated that the sediments have accumulated about 62, 40, 90 and 80 percent of cadmium, copper, lead, and zinc, respectively, in the eastern rivers of the United States (EPA 1998, Uddin 2017). 
Therefore, considering the presence of sediment loads having very high sorption rates, and the effects of sorption process by sediments on the advection and dispersion of these pollutants is important.

After being absorbed by the sediment particles, heavy metal ions are transferred from the dissolved phase into the absorbed phase. This process can be seen as a self-cleaning process of the rivers (Fornster and Gottfried 1981; Herut et al. 1995; Bird and Evenden 1996). It should be mentioned that, there are two approaches for description of this phenomenon in the aquatic systems. Some researchers supposed that the distribution of pollutants may be described as an equilibrium process by an instantaneous partitioning between the dissolved and the adsorbed phases (Falconer and Lin 2003; Wu et al. 2005). Others considered the sorption as a kinetic process (Jonsson and Worman 2001; Jonsson et al. 2004; Huang et al. 2007; Roshanfekr et al. 2008; and Huang 2009). Longitudinal dispersion coefficient can be affected by many hydrodynamic and geometrical parameters, and as a result the dispersion characteristic may vary from one river to another. Till now, three methods, namely the integral method, dye tracing measurements and empirical formulae have been widely used to estimate the longitudinal dispersion coefficient (Zeng and Huai, 2014).

When the pollutants enter the rivers, they may move through the flow velocity along with the river and spread vertically, transversely, and longitudinally due to turbulent diffusion within the channel and absorbed into the suspended and bed sediments through the sorption process. The advection-dispersion equation for the pollutants is defined by considering the absorption process, as follows (Runkel and Bencala 1995):

$66 \quad \frac{\partial \mathrm{C}}{\partial \mathrm{t}}=-\mathrm{V} \frac{\partial \mathrm{C}}{\partial \mathrm{x}}+\mathrm{D}_{\mathrm{L}} \frac{\partial^{2} \mathrm{C}}{\partial \mathrm{x}^{2}}-\rho \frac{\partial \mathrm{q}}{\partial \mathrm{t}}$

where, $\mathrm{C}$ is the concentration of solution $(\mathrm{g} / \mathrm{lit}), \mathrm{V}$ is flow velocity $(\mathrm{m} / \mathrm{s}), \mathrm{D}_{\mathrm{L}}$ is longitudinal dispersion coefficient $\left(\mathrm{m}^{2} / \mathrm{s}\right), \rho$ is the sediment concentration $(\mathrm{g} / \mathrm{lit})$, and $\mathrm{q}$ is the amount of cadmium absorbed in $\mu \mathrm{g}$ per unit weight of the sediments. The expression $\partial \mathrm{q} / \partial \mathrm{t}$ represents the release of cadmium ions from the soluble phase by the sorption process, for which, various equilibrium and kinetics models have been proposed.

Until now, many researchers have studied numerically and analytically the advection-dispersion equation with considering the sorptive effects of pollutants in groundwater (van Kooten 1996, Williams and Tomasko 2008, Bruining et al. 2012, Singh and Das 2016, Jaiswal and Gulrana 2019, and Pillai and Raizada 2021) and surface water resources (Phillips et al. 1995, Ng 2000a, b, 2001, 2006), Revelli and Ridolfi 2002, 2003 and Yip and $\mathrm{Ng}$ 2003, and Mahdavi et al. 2008).

Purnama (1995) found that, for low sorption rates, the boundary retention increases the dispersion rate and considers as the main effect suppressing the boundary absorption, which decreases the dispersion rate. It 
was, however, pointed out by Jiang and Grotberg (1993) that, for dispersion in oscillatory tube flow, the wall absorption, when it is weak, may increase or decrease the dispersion depending on the oscillation frequency. $\mathrm{Ng}$ (2000a) studied the effects of sorptive exchange on the transport of a chemical in a sediment-laden open-channel flow. He found that, for sufficiently large particles and solid fractions, enhancement of the longitudinal dispersion coefficient due to the sorptive exchange can be significant and should be included in a comprehensive model. Revelli and Ridolfi $(2002,2003)$ have investigated the dispersion in sediment-laden streams where the chemical may undergo sorptive exchange with suspended sediments and nonlinear decay reactions. $\mathrm{Ng}$ (2006) has extended the work of Jiang and Grotberg (1993) to dispersion in tube flow subject to both an irreversible process of absorption and a reversible phase exchange process at the tube wall. It has been found that the kinetics of the phase exchange will have dramatic effects on the dispersion, including intensifying the otherwise weak effects due to the wall absorption. Williams and Tomasko (2008) developed an analytical solution of the one-dimensional contaminant transport undergoing advection, dispersion, sorption, and firstorder decay, subject to a first-order decaying contaminant concentration. They pointed out that this solution can be used to model the transport of radioactively decaying contaminants and remediation of recalcitrant NAPL. In both cases the boundary concentration can exhibit first-order source decay and undergo transport decay at a different rate.

Mahdavi et al. (2013) investigated the effect of sorption of cadmium to sediments through an experimental and numerical study. Their results showed that sorption process reduces the dispersion coefficient but has no effect on advection rate. The results also indicate that the linearization method of estimating sorption parameters is unsuitable. It was also found that a pseudo second-order model for kinetic sorption improves the results obtained in comparison with a first-order model. Comparison between the kinetic and equilibrium models showed that assuming equilibrium conditions underestimates transport velocity. One of the gaps of this study was the experiment just performed at one sediment concentration. Ghoveisi et al. (2014) examined the effect of flow velocity, sediment movement type and concentration in the kinetic adsorption and transport of cadmium in both bed and suspended load conditions. Their results showed that the adsorption rate is directly connected with sediment motion type and flow velocity. For the bed-load conditions, it was observed that the equilibrium capacity increased by $20 \%$ as the flow velocity changed from 0.35 to $0.7 \mathrm{~m} / \mathrm{s}$. However, for suspended load conditions, the equilibrium capacity was not significantly affected by the flow velocity or sediment motion type. It was experimentally deduced that increasing the sediment concentration load by $300 \%$ 
would decrease the equilibrium cadmium adsorption in unit mass by $170 \%$ and $250 \%$ for bed and suspended

108 loads, respectively.

Hlushkou et al. (2014) developed a microscopic numerical model combining simulations of

110 advective-diffusive transport with a stochastic approach to the sorption process at the solid-liquid interface for

111 flow through a circular tube. The retention factor of an adsorbed solute is constructed by independent

112 adjustment of the adsorption probability and mean adsorption sojourn time. The presented three-dimensional

113 modeling approach can realize any microscopic model of the adsorption kinetics based on a distribution of

114 adsorption sojourn times expressed in analytical or numerical form. They addressed the impact of retention

115 factor, adsorption probability, and distribution function for adsorption sojourn times on solute dispersion

116 depending on the average flow velocity. Their results demonstrated that the distribution function for adsorption

117 sojourn times is a key parameter affecting dispersion and show that models of advection-diffusion-sorption

118 cannot describe mass transport without specifying microscopic details of the sorption process. In contrast to

119 previous one-dimensional stochastic models, the presented simulation approach can be applied as well to study

120 systems where diffusion is a rate-controlling process for adsorption. Wang and Chen (2016) analytically studied

121 the evolution of two-dimensional concentration distribution for solute dispersion in a laminar open-channel flow with bed absorption. Their results showed the extremely non-uniform cross-sectional concentration distribution, and demonstrated that concentration at the bed instead of the mean should be used for reliable quantification of the absorption flux. Mondal et al. (2020) describes the longitudinal dispersion of passive tracer materials released into an incompressible viscous fluid, flowing through a channel with walls having first-order reaction. Its model was based on a steady advection-diffusion equation with Dirichlet's and mixed boundary conditions, and whose solution represents the concentration of the tracers in different downstream stations. For imposing the boundary conditions. A finite difference implicit scheme was used to solve the advection-diffusion equation in the computational region, and an inverse transformation was employed for the solution in the physical region. They shoed how the mixing of the tracer molecule influenced by the shear flow and due to the action of the absorption parameter at both the walls of the channel.

While much work has been performed on the longitudinal coefficient in channels and rivers, there are 133 few studies in the literature, particularly looking into the effects of sorption process on advection and dispersion of heavy metals. On the other hand, there is a gap in knowledge about the effect of heavy metal sorption by natural river sediments in different concentration on advection-dispersion processes. For this purpose, first, the absorption of cadmium ions by riverbed sediments were experimentally investigated for different sediment 
137 concentrations to find the adsorption parameters. Accordingly, the research objectives are as follows: 1 . study of

138 the effect of sediment concentrations on the longitudinal dispersion coefficient; 2 . analysis of the advection-

139 dispersion equation with respect to the sorption term; and 3. numerical solution of the advection-dispersion

140 equation with respect to the sorption term. We are also looking for a relationship between the longitudinal

141 dispersion coefficient and a parameter representative of cadmium sorption rate of the bed sediments, in which,

142 the sediment and cadmium concentrations are considered.

143

144 Materials and Methods

145 Experimental Investigations

146 The experiments of this study were conducted in a circular flume with a mean diameter of $1.6 \mathrm{~m}$, width 147 of $0.20 \mathrm{~m}$ and a depth of $0.15 \mathrm{~m}$ (Fig. 1) placed on a platform of $2 \times 2 \mathrm{~m}^{2}$. The water-sediment mixture was run 148 using two pedals within the flume. In order to remove any possible impurities (especially, the pollutants due to 149 previous experiments), the flume was filled with $0.1 \% \mathrm{HNO}_{3}$ and was run for $1 \mathrm{hr}$ before each experiment. It was then thoroughly rinsed and filled up to $0.13 \mathrm{~m}$ (130 lit) with deionized water. The environmental parameters of $\mathrm{pH}$ and $\mathrm{EC}$ were respectively adjusted using $\mathrm{NaOH}$ or $\mathrm{HNO}_{3}$ and $\mathrm{NaCl}$, which were constant throughout the experiments $(\mathrm{EC}=800 \pm 10 \mu \mathrm{S} / \mathrm{cm}, \mathrm{pH}=7.5 \pm 0.1)$. In addition, all the experiments were conducted at temperature of $25^{\circ} \mathrm{C}$, adjusting by two $300 \mathrm{~W}$ aquarium heaters. A stock solution of $1000 \mathrm{ppm}$ cadmium was prepared for all experiments. Cadmium measurements were conducted by using an ICP-OES (Varian VISTA-MPX device). The detection limit for the cadmium ion was $0.0005 \mathrm{ppm}$. Iran) and were taken from upper 0-15 cm layer of the deposits at the places with low flow rates as sedimentation was assumed to occur (Jain and Ram, 1997). The samples were washed several times with distilled water to remove physical earthen impurities. Then, prior to experiments, they were dried in a hot air oven at $110^{\circ} \mathrm{C}$ for 24 hrs. A sediment size of $0.53 \mathrm{~mm}$ was selected by using standard sieving apparatus (particles remained between sieves No. 30 and 40). The cation exchange capacity (CEC) of the riverine sediments was measured using Bower et al.'s method (Bower et al. 1952) equal to $13.873 \mathrm{meq} / 100 \mathrm{gr}$. Besides, the general physical- 
chemical features of sediment samples revealed that these samples were mainly composed of $\mathrm{SiO}_{2}(54 \mathrm{wt} \%)$, $\mathrm{AlSi}_{3} \mathrm{O}_{8}\left(14.4\right.$ wt \%), $\mathrm{Fe}_{2} \mathrm{O}_{3}(7.5$ wt \%), $\mathrm{CaO}(6.4 \mathrm{wt} \%)$, and other minerals (8.34 wt \%).

Experimental investigations in this study were performed in two parts: sorption and dispersion experiments. First, the sorption experiments were conducted in order to obtain the sorption parameters $(\mathrm{k}$ and $\mathrm{q}_{\mathrm{e}}$ ) as a function of cadmium and sediment concentrations, which they are needed for numerical modeling. During these experiments, the cadmium solution (with the concentrations of 150, 460 and $770 \mathrm{ppb}$ ) was first injected throughout the flume. The cadmium plume was then spread through the flume. After a certain time and reaching an equilibrium conditions, three samples were taken from different points of the flume for measuring the initial concentrations $\left(\mathrm{C}_{0}\right)$ and to ensure a constant cadmium concentration throughout the flume. A thin layer of bed sediments were then spilled throughout the flume bed with the concentrations of 3, 12, and $20 \mathrm{gr} / \mathrm{lit}$. The experiment was started by taking $50 \mathrm{~mL}$ samples at a given point in the centreline of the flume in different times. According to Mahdavi et al. (2013), the sorption process were kinetically investigated by taking the samples in different times of $0,1,2,5,10,15,30,45,60,90,120,180,240$, and $300 \mathrm{~min}$. The amount of adsorbed cadmium at each time (q) is calculated, as follows:

$\mathrm{q}=\frac{\left(\mathrm{C}_{0}-\mathrm{C}\right) \forall}{\mathrm{W}}$

where, $\mathrm{C}_{0}$ is the initial cadmium concentration $(\mathrm{t}=0)$ and $\mathrm{C}$ is the cadmium concentration at different times (ppb), $\mathrm{V}$ is the volume of the water (130 lit), and $\mathrm{W}$ is the weight of the sediments (gr). For the kinetic modeling, a pseudo second order equation is used (Ho and McKay 1999; Azizian 2004; and Mahdavi et al. 2013), as follows:

$\frac{\partial \mathrm{q}}{\partial \mathrm{t}}=\mathrm{k}_{2}\left(\mathrm{q}_{\mathrm{e}}-\mathrm{q}\right)^{2}$

where, $\mathrm{k}_{2}$ is the second order rate coefficient and $\mathrm{q}_{\mathrm{e}}$ is the equilibrium adsorbed cadmium. Integrating this equation for the boundary conditions of $\mathrm{t}=0$ to $\mathrm{t}=\mathrm{t}$ and $\mathrm{q}=0$ to $\mathrm{q}=\mathrm{q}$, gives:

$\frac{\mathrm{t}}{\mathrm{q}_{\mathrm{t}}}=\frac{1}{\mathrm{k}_{2} \mathrm{q}_{\mathrm{e}}^{2}}+\frac{1}{\mathrm{q}_{\mathrm{e}}} \mathrm{t}$

The sorption experiments with different initial cadmium concentrations are used in order to determine the best kinetic equation and to estimate the sorption parameters $\mathrm{k}_{2}$ and $\mathrm{q}_{\mathrm{e}}$. In order to estimate the kinetic sorption parameters, there are two methods (Mahdavi et al. 2013). The first method is applying the least square method to the linear transformed kinetic model (Eqs. 3 and 4). However, Jiang et al. (2007) and Ho (2006) showed that 
it is better to use non-linear least square method for the original non-linear equation. Therefore, in this study, both methods are used and compared.

In the second part of the experiments, the dispersion process was investigated in a different manner from the sorption experiments. In this section of the tests, a thin layer of sediments were first spread over the bottom of flume at a specified concentration (3, 12, and $20 \mathrm{~g} / \mathrm{lit}$ ). After adjusting the environmental parameters (temperature, $\mathrm{pH}$, and EC), the cadmium solution with a given concentration was injected in one point of the flume $(\mathrm{x}=0)$; then the cadmium plume was transported and spread longitudinally through the flume by advection and dispersion processes, respectively, until it dispersed throughout the flume. It should be mentioned that the transverse spreading of the plume was ignored because the flume width is small. The changes in the cadmium concentrations were monitored at a distance of $\mathrm{x}=1.256 \mathrm{~m}$ from the injection point. The samples were taken from this point at about $3 \mathrm{~s}$ intervals. By repeating these experiments with and without the presence of sediments, the effect of sorption by sediments can be investigated on longitudinal dispersion of the cadmium. The list of conducted experiments as well as experimental conditions are presented in table 1. The experiments were always started with the constant flow velocities of about $0.2 \mathrm{~m} / \mathrm{s}$. In order to estimate the flow velocity, the salt was only injected at once from one point of the flume and the conductivity (EC) values were measured at this point with time, and the average velocity was measured using the measured time for a number of cycles and the spatial distance between the peaks.

Table 1. Conducted experiments and experimental conditions

\section{Numerical Modeling}

Apollo and Postman (1993)'s method was used to solve Eq. (1), numerically. Indeed, the advantage of this procedure is that the different expressions of advection, dispersion, and absorption are individually solved at each step. In other word, at a certain time step, the effect of the advection on the cells is first applied. Then, the effect of the dispersion is calculated in each cell; after that on the resulting cells from advection and dispersion expressions the effect of the absorption will be applied. The advantage of this method is that one can easily add other chemical or physical formulas to the model. In addition, each process can be solved with the most appropriate numerical method.

Figure 1. ABOUT HERE. 


\section{Results and Discussion}

\section{Results of Sorption Experiment}

In this study, the advection and dispersion of cadmium ion at the presence of river bed sediments were investigated. As mentioned before, the sorption characteristics of the river sediments were first investigated. In addition, the kinetic sorption was investigated in several steps. The overall results of these experiments showed that for most sorption processes, the cadmium sorption rate by bed sediments consists of three phases: the first phase (rapid absorption), the second phase (transition) and the third phase (almost flat) (Fig. 2).

Figure 3 shows the effect of sediment concentration on the cadmium sorption rate for initial cadmium concentrations of 150,460 and $770 \mathrm{ppb}$. As can be seen, by increasing sediment concentrations, the absorbed cadmium per unit weight of sediment is reduced. According to this figure, with increasing sediment concentrations from 3 to $20 \mathrm{~g} /$ lit, the equilibrium adsorbed cadmium per unit weight of sediment $(1 \mathrm{gr})$ is reduced from 30 to $6.25,86.68$ to 22.52 , and 67.66 to $36.5 \mu \mathrm{g}$. Although the sorption rate is lower for the highest sediment concentration ( $20 \mathrm{gr} / \mathrm{lit}$ ), it can be said that by increasing the sediment concentrations, the sorption percentage increases. In these experiments, by increasing the sediment concentrations, the cadmium removal percentage increased from 50 to $78.15 \%$ (for Cd concentration of $150 \mathrm{ppb}$ ) from 47.27 to $84.9 \%$ (for the concentration of $460 \mathrm{ppb}$ ) and from 41 to $80.21 \%$ (for Cd concentration of $770 \mathrm{ppb}$ ). In other words, it can be concluded that by increasing the sediment concentrations in the solution and because of competition between sediments, the contribution of each gram of sediment in the solution decreases, however, the total absorbed cadmium increases.

The following explanations can be expressed for these changes: 1) at the initial stage of adsorption process, the sediment surface provided more adsorption sites, which contributed to rapidly increased adsorption rate. Due to the negative-charged surface of sediments, it could combine with metal cations through Coulomb force, and this process could be considered as pseudo-adsorption. 2) specific adsorption happened through 
chemical reaction between $\mathrm{Cd}(\mathrm{II})$ and sediment surface was followed. However, it would change the property of surface electric charge. Increased positive sites would prevent the adsorption of $\mathrm{Cd}(\mathrm{II})$; and 3) available sorption sites became limiting factor along with increasing adsorption amount. (González Costa et al., 2017; Markiewicz-Patkowska et al., 2005; Vibhawari et al., 2010, Huang et al., 2019). The results of Jain and Ram (1997), Jain and Sharma (2002), Ho (2003 and 2006), Mahdavi et al. (2008) are consistent with the results of the present study.

Table 2. Results of calculations of sorption parameters.

\section{Results of Dispersion Experiments}

In order to estimate the longitudinal dispersion coefficient and investigate the effect of cadmium sorption

by river bed sediments on this coefficient, some experiments were performed. The results of these experiments are used for calibration and validation of the numerical model. These experiments were performed in three sediment concentrations of 3,12 , and $20 \mathrm{gr} / \mathrm{lit}$ as well as sediment-free conditions (control experiment; $\mathrm{C}_{\mathrm{s}}=0$ ). The results of dispersion experiments for runs No. AD05 and AD08 $\left(\mathrm{C}_{\mathrm{s}}=0\right)$ and at the presence of bed sediment with a concentration of $20 \mathrm{gr} / \mathrm{lit}$ and cadmium concentration of $460 \mathrm{ppb}$ is shown in Fig. 4 . As can be seen, the presence of sediments has two major effects on time distribution curve of concentration cadmium. First, due to the cadmium sorption by sediments, the peak values have decreased relative to the sediment-free state. Second, the difference between the minimum and maximum values of each peak has increased.

Figure 4. ABOUT HERE. (1995)'s method) was applied to numerically solve Eq. 1.

According to Fig. 5, in a circular flume, cell 1 is located next to the last cell (cell n). Therefore, its value is calculated at the next step using cells 1,2 and $\mathrm{n}$ at a previous time step. The cell $\mathrm{n}$ is also calculated by cells 1 , $\mathrm{n}-1$ and $\mathrm{n}$. 
284 The initial condition is that at time $\mathrm{t}=0$, the concentration across the flume other than the cadmium injection region is zero:

286

$\left\{\begin{array}{l}\mathrm{C}=0 \\ \mathrm{C}=\mathrm{C}_{\mathrm{in}}\end{array} \quad\right.$ for $\mathrm{t}=0$ and $\forall \mathrm{x}$

Besides, the boundary condition is that the cadmium concentrations at $\mathrm{x}=0$ and $\mathrm{x}=\mathrm{L}$ are equal at all times:

$\mathrm{C}_{0}=\mathrm{C}_{\mathrm{L}} \quad$ for $\quad \forall \mathrm{t}$

290 In order to estimate the longitudinal dispersion coefficient without sediments and at the presences of sediments with different concentrations, a numerical model was developed in MATLAB and calibrated by experimental data. Therefore, the model was run for different flow velocities and dispersion coefficients and the best coefficient was selected after comparing with the experimental data and calculating Sum of squared error (SSE). correlation between experimental results and numerical modelling.

Figure 7 shows the breakthrough curve of cadmium concentration in a sediment-free experiment (solid line) and for a sediment concentration of $20 \mathrm{gr} /$ lit (dotted line). As can be seen, the presence of sediments significantly affects advection and dispersion of cadmium, by increasing the cadmium sorption. Increasing the adsorptive capacity of the sediment particles delays breakthrough of the adsorbing solute. Besides, the leading edge of the concentration profile is similar in shape to the zero adsorption case (sediment-free experiment). It has been obviously shown that the sorption process by sediments at maximum concentration reduces the longitudinal dispersion coefficients. numerical modelling has a great capability in estimating the concentration of pollutant in the flow. 


\section{Effect of sorption on longitudinal dispersion coefficient}

As shown in figures 5 and 7, the presence of sediments and sorption process reduces the longitudinal

317 dispersion of cadmium. In this study, in order to evaluate the effect of sorption by sediment, a new parameter, 318 named "absorption ratio $\left(A_{R}\right)$ " was defined, as follows:

$$
A_{R}=\frac{C_{0}-C_{50}}{t_{50}}
$$

in which, $\mathrm{C}_{0}$ is the initial concentration $(\mu \mathrm{g} / \mathrm{lit}), \mathrm{C}_{50}$ is cadmium concentration when the sorption percentage is $50 \%(\mu \mathrm{g} / \mathrm{lit})$ and $t_{50}$ is the required time $(\mathrm{min})$ to achieve an sorption percentage of $50 \%$.

The results of the analysis of cadmium advection and dispersion experiments in the presence of bed sediments are presented in table 3 . As can be observed, with increasing the sediment concentrations, the sorption rate of sediments increased and the longitudinal dispersion coefficient decreased by 38,36 and $33 \%$ for cadmium concentrations of 150,460 and $770 \mu \mathrm{g} /$ lit, respectively.

In column 6 of table $3, \lambda$ is the longitudinal dispersivity, derived by dividing the longitudinal dispersion coefficient to the average flow velocity $\left(=\mathrm{D}_{\mathrm{L}} / \mathrm{V}\right.$, in $\left.\mathrm{m}\right)$. As can be seen, with increasing the sediment concentrations in a constant cadmium concentration, the longitudinal dispersion coefficients are decreased. The range of this parameter is $0.041-0.067,0.041-0.065,0.04-0.058 \mathrm{~m}$ for cadmium concentrations of 150,460 , and $770 \mathrm{ppb}$, respectively. in figure 9. This figure shows that with increasing sorption ratio, the longitudinal dispersion coefficient decreased. The reduction in the longitudinal dispersion coefficients is minimized for high sorption ratio. As it is observed, there is a critical value for $A_{R}$, in which, the longitudinal dispersion coefficient will not decrease for values greater than this critical value. 

dimensional dispersion coefficients $\left(\mathrm{D}_{\mathrm{L}} / \mathrm{Vh}\right)$ was used. The following equation was developed between the

343 dimensionless dispersion coefficients and the sorption ratio:

$$
\frac{D_{L}}{V h}=16.05\left(1.02+e^{-0.001 A_{R}}\right)
$$

where, $\mathrm{D}_{\mathrm{L}}$ is the longitudinal dispersion coefficient, $\mathrm{V}$ is the average flow velocity, $\mathrm{h}$ is the average flow depth, and $A_{R}$ is the absorption ratio. Two statistical indices of mean absolute error and sum of squared errors were used and the results showed that the average error of this relationship is $8.28 \%$ and the sum of the squared error is 0.0248 . These values represent the very great accuracy of this relationship in estimating the longitudinal dispersion coefficient of cadmium in the presence of river bed sediments.

\section{Conclusions}

This study is solely focused on the effects of sorptive exchange with river bed sediments on the mass transport of cadmium in an open-channel flow. In this research, the effect of cadmium sorption by river bed sediments on the advection and dispersion processes was investigated experimentally and numerically. The results of dispersion experiments showed that with increasing the sediment concentrations, the sediment sorption rate increased and the longitudinal dispersion coefficient decreased by about 38,36 and 33 percent for cadmium concentrations of 150,460 and $770 \mathrm{ppb}$, respectively. In addition, by increasing the cadmium concentrations in the solution, the changes in the longitudinal dispersion coefficient are decreased. Furthermore, a relationship was developed using non-dimensional longitudinal dispersion as a function of absorption ratio. The results of this analysis showed high ability of developed relationship to estimate longitudinal dispersion coefficient and to consider the effect of cadmium absorption by sediments on the longitudinal dispersion coefficient. In general, such strong dependence of the dispersion coefficient on the kinetics sorptive exchange may lead to interesting phenomena especially during the initial developing stage of the transport. A future study into these phenomena is worth pursuing, especially for other heavy metals with high concentrations as well as a wide range of sediment concentrations and flow velocities. 


\section{Consent to participate}

Not applicable

Consent to Publish

Not applicable

\section{Authors Contributions}

Mohsen Nasrabadi, as former PhD Candidate, performed the experiments and analyzed and interpreted the data and he was a major contributor in writing the manuscript. Ali Mahdavi Mazdeh is the co-supervisor of this $\mathrm{PhD}$ thesis, and Mohammad H. Omid is the main supervisor of this $\mathrm{PhD}$ thesis. All authors read and approved the final manuscript.

\section{Funding}

There is no funding sources for the research reported

\section{Competing Interests}

The authors declare that they have no competing interests.

\section{Data Availability}

\section{References}

394 Appelo CA and Postma D (1993) Geochemistry, Groundwater and Pollution. Balkema, Rotterdam.

Azizian S (2004) Kinetic models of sorption: a theoretical analysis. Journal of Colloid and Interface Science, 276: 47-52.

Bird GA, and Evenden WG (1996) Transfer of 60Co, 65Zn, 95Tc, 134Cs and 238U from water to organic sediment. Water, Air, Soil Pollut. 86: 251-261. 
Bower CA, Reitmeir RF, and Fireman M (1952) Exchangeable cation analysis of saline and alkali soils. Soil Sci. 73: 251-261.

Bruining H, Darwish M, Rijnks A (2012) Computation of the Longitudinal and Transverse Dispersion Coefficient in an Adsorbing Porous Medium Using Homogenization. Transp Porous Med. 91: 833-859.

EPA (2003) National primary drinking water standards, U. S. Environmental Protection.

Falconer RA and Lin B (2003) Hydro-environmental modelling of riverine basins using dynamic rate and partitioning coefficients. International Journal of River Basin Management, 1(1): 81-89.

Fornster U and Gottfried TW (1981) Metal pollution in the aquatic environment, 2nd Ed., Berlin: SpringerVerlag.

Ghoveisi H, Mahdavi Mazdeh A, Farhoudi J, Omid MH (2014) The effect of sediment motion on adsorption of cadmium. Proceedings of the ICE - Water Management 167(4): 238-245. doi:10.1680/wama.12.00103.

González Costa JJ, et al. (2017) Soil $\mathrm{Cd}, \mathrm{Cr}, \mathrm{Cu}, \mathrm{Ni}, \mathrm{Pb}$ and $\mathrm{Zn}$ sorption and retention models using SVM: variable selection and competitive model. Sci. Total Environ. 508: 593-594.

Herut B, Hornung H, Kress N, Krom MD, and Shirav M (1995) Trace metals in sediments at the lower reaches of Mediterranean coastal rivers, Israel. Water Sci. Technol. 32(9-10): 239-246.

Hlushkou D, Gritti F, Guiochon G, Seidel-Morgenstern A, Tallarek U (2014) Effect of Adsorption on Solute Dispersion: A Microscopic Stochastic Approach. Anal. Chem. 86: 4463-4470.

Ho YS and McKay G (1999) Pseudo-second order model for sorption processes. Process Biochemistry. 34: $451-465$.

Huang SL (2009) Two-dimensional numerical modeling of chemical transport-transformation in fluvial rivers: formulation of equations and physical interpretation. Journal of Hydroinformatics. 11(2): 106-118.

Huang SL, Wan ZH, Smith P (2007) Numerical modeling of heavy metal pollutant transport-transformation in fluvial rivers. Journal of Hydraulic Research. 45(4): 451-461.

Huang Y, Fu C, Li Z, Fang F, Ouyang W, Guo J (2019) Effect of dissolved organic matters on adsorption and Heterogeneous Porous Medium. Applications \& Applied Mathematics. 14(1): 485-496. 
Jain CK and Ram D (1997) Adsorption of metal ions on bed sediments, Hydrol. Sci. J. 42(5): 713-723.

430 Jiang Y and Grotberg J (1993) Bolus contaminant dispersion in oscillatory tube flow with conductive walls. J. Biomech. Eng. Trans. ASME 115: 424-431.

Jiang H, Xu Y, Zhang J, Zhang L, and Han RP (2007) Pseudo second order kinetic model for the biosorption of lead onto waste yeast: A comparison of linear and nonlinear methods and error analysis. Life Science Journal. 4(4): 42-45.

Jonsson K and Worman A (2001) Effect of sorption kinetics on the transport of solutes in streams. The Science of the Total Environment. 266: 239-247.

Jonsson K, Johansson H, and Worman A (2004) Sorption behavior and long-term retention of reactive solutes in the hyporheic zone of streams. Journal of Environmental Engineering ASCE. 130(5): 573-584.

Mahdavi A, Omid MH and Ganjali MR (2008) Effect of bed load transport on kinetic sorption in a circular flume. Proceedings of International Conference on Fluvial Hydraulics, RiverFlow2008, Cesme-Izmir, Turkey. Kubaba Congress Department and Travel Services, Ankara, Turkey, 2485-2491.

Mahdavi A, Kashefipour SM, and Omid MH (2013) Effect of sorption process on cadmium transport. Proceedings of the Institution of Civil Engineers-Water Management. 166(3): 152-162.

Markiewicz-Patkowska J et al. (2005) The interaction of heavy metals with urban soils: sorption behaviour of $\mathrm{Cd}, \mathrm{Cu}, \mathrm{Cr}, \mathrm{Pb}$ and $\mathrm{Zn}$ with a typical mixed brownfield deposit. Environ. Int. 31, 513.

Mondal KK, Dhar S and Mazumder BS (2020) On dispersion of solute in steady flow through a channel with

Ng CO (2000a) Chemical transport associated with discharge of contaminated sediment particles to a steady open-channel flow. Physics of Fluids. 12: 136-144.

Ng CO (2000b) Dispersion in sediment-laden stream flow. Journal of Engineering Mechanics ASCE. 126(8): 779-786.

$\mathrm{Ng}$ CO (2006) Dispersion in open-channel flow subject to the processes of sorptive exchange on the bottom and air-water exchange on the free surface. Fluid Dynamic Research. 38(6): 359-385.

$\mathrm{Ng} \mathrm{CO} \mathrm{(2001)} \mathrm{Effects} \mathrm{of} \mathrm{kinetic} \mathrm{sorptive} \mathrm{exchange} \mathrm{on} \mathrm{solute} \mathrm{transport} \mathrm{in} \mathrm{open} \mathrm{channel} \mathrm{flow.} \mathrm{Journal} \mathrm{of} \mathrm{Fluid}$ Mechanics. 446: 321-345.

Phillips CG, Kaye SR, and Robinson CD (1995) Time-dependent transport by convection and diffusion with exchange between 2 phases. Journal of Fluid Mechanics. 297: 373-401. 
Pillai K, Raizada A, (2021) Modeling Transport and Adsorption of Arsenic Ions in Iron-Oxide Laden Porous Media. Part I: Theoretical Developments. Water, 13, 779. https://doi.org/10.3390/w13060779.

Purnama A (1995) The dispersion of chemically active solutes in parallel flow. Journal of Fluid Mechanics, 290: 263-277. DOI: https://doi.org/10.1017/S0022112095002503.

Revelli R and Ridolfi L (2002) Influence of suspended sediment on the transport processes of nonlinear reactive substances in turbulent streams. Journal of Fluid Mechanics. 472: 307-331.

Revelli R and Ridolfi L (2003) Transport of reactive chemicals in sediment-laden streams. Advances in Water Resources. 26(8): 815-831.

Roshanfekr A, Kashefipour SM and Jafarzadeh N (2008) Numerical modeling of heavy metals for riverine systems using a new approach to the source term in the ADE. Journal of Hydroinformatics. 10(3): 245255.

Runkel RL and Bencala KE (1995) Environmental Hydrology (Singh, V.P.(ed.)). Kluwer Academic Publishers, Dordrecht, The Netherlands, Chapter 5, 137-164.

Singh MK and Das P (2016) Analytical Solution for Solute Transport Modeling along the Unsteady Groundwater Flow in Porous Medium, Future Challenges in Earth Sciences for Energy and Mineral Resources, Geological Survey of India. 130-135.

Uddin MK (2017) A review on the adsorption of heavy metals by clay minerals, with special focus on the past decade. Chemical Engineering Journal. 308: 438-462.

Van Kooten J J A (1996) A method to solve the advection-dispersion equation with a kinetic adsorption isotherm Advances in Wafer Resources. 19(4): 193-206.

Vibhawari et al. (2010) Single and competitive sorption of heavy metal ions $\left(\mathrm{Cd}^{2+} \& \mathrm{Cu}^{2+}\right)$ on a clayey soil. J. Chem. 7, S27-S34.

Wang P and Chen GQ (2016) Solute dispersion in open channel flow with bed absorption. Journal of Hydrology. 543(Part B): 208-217.

Williams GP, and Tomasko D (2008) Analytical Solution to the Advective-Dispersive Equation with a Decaying Source and Contaminant Journal of Hydrologic Engineering. 13(12): 1193-1196.

Wu Y, Falconer RA and Lin B (2005) Modeling trace metal concentration distributions in estuarine waters. Estuarine, Costal and Shelf Science. 64: 699-709.

Yip TL and Ng CO (2003) Dual-species transport subject to sorptive exchange in pipe flow. Journal of Applied Mechanics, Transactions of the ASME. 70(4): 550-560. 

environment Research 8: 2-8.

491 


\section{$492 \quad$ List of tables}

493 Table 1 Conducted experiments and experimental conditions.

494 Table 2 Results of calculations of sorption parameters.

495 Table 3 Results of the analysis of cadmium advection and dispersion experiments.

496 


\section{Figure Captions}

498 Figure 1 Plan and cross section of the circular flume

499 Figure 2 Different phases of the cadmium sorption.

500 Figure 3 The effect of sediment concentration on the cadmium sorption

501 Figure 4 Time distribution of cadmium concentration ( $p p b$ 460) without and with sediment concentration of 20

$502 \mathrm{~g} / \mathrm{lit}$.

503 Figure 5 General Scheme for Numerical Modelling

504 Figure 6 Time distribution of cadmium concentration; numerical results and experimental data.

505 Figure 7 Time variations of cadmium concentrations with river bed sediments; numerical results and 506 experimental data.

507 Figure 8 Measured data versus numerical modelling

508 Figure 9 Changes in longitudinal dispersion coefficient of cadmium versus sorption ratio 
Figures

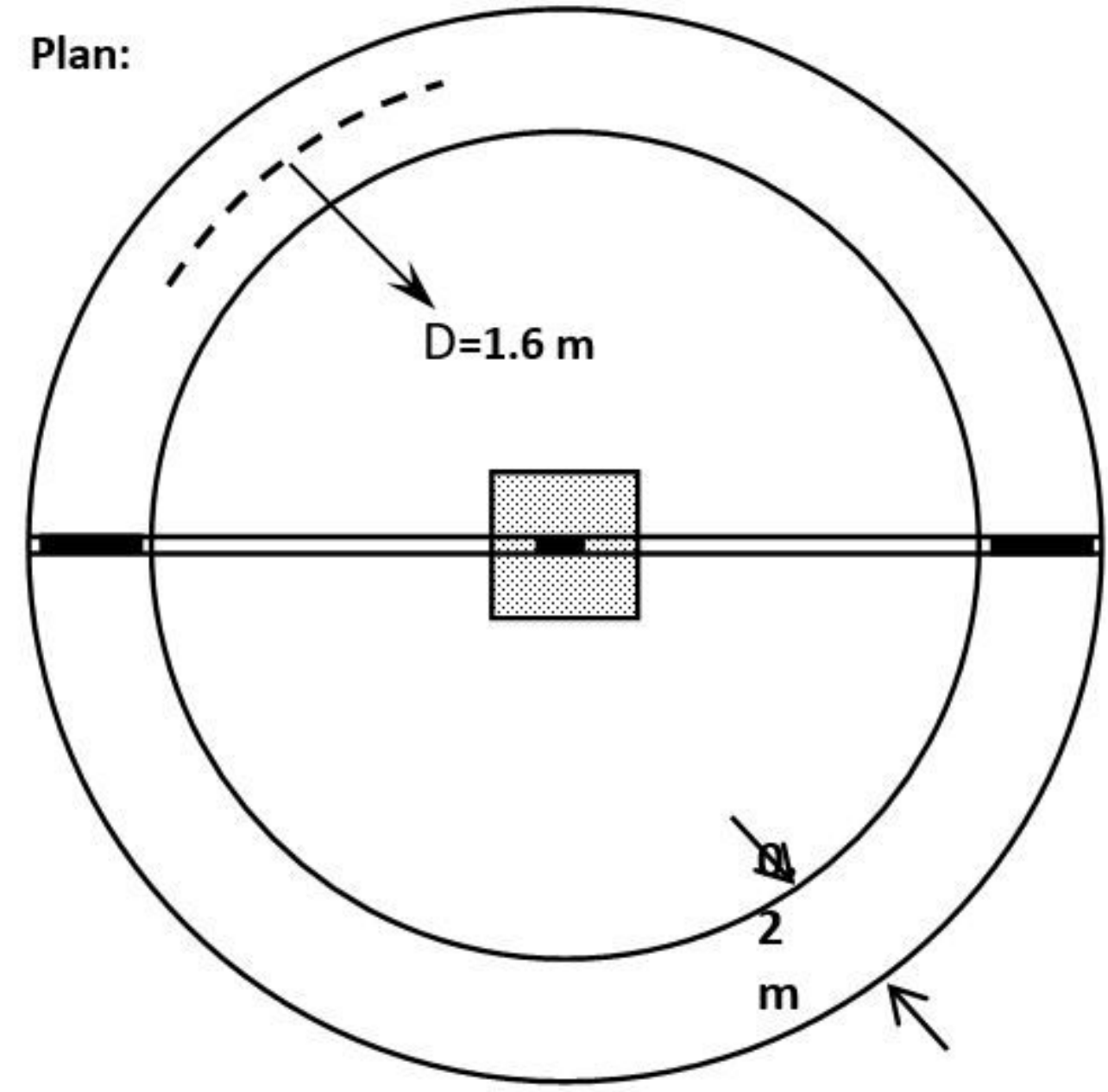

Cross Section:

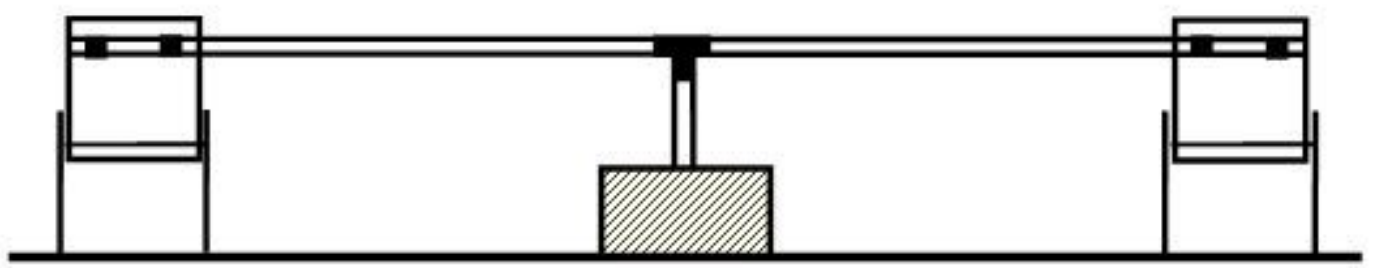

Figure 1

Plan and cross section of the circular flume 


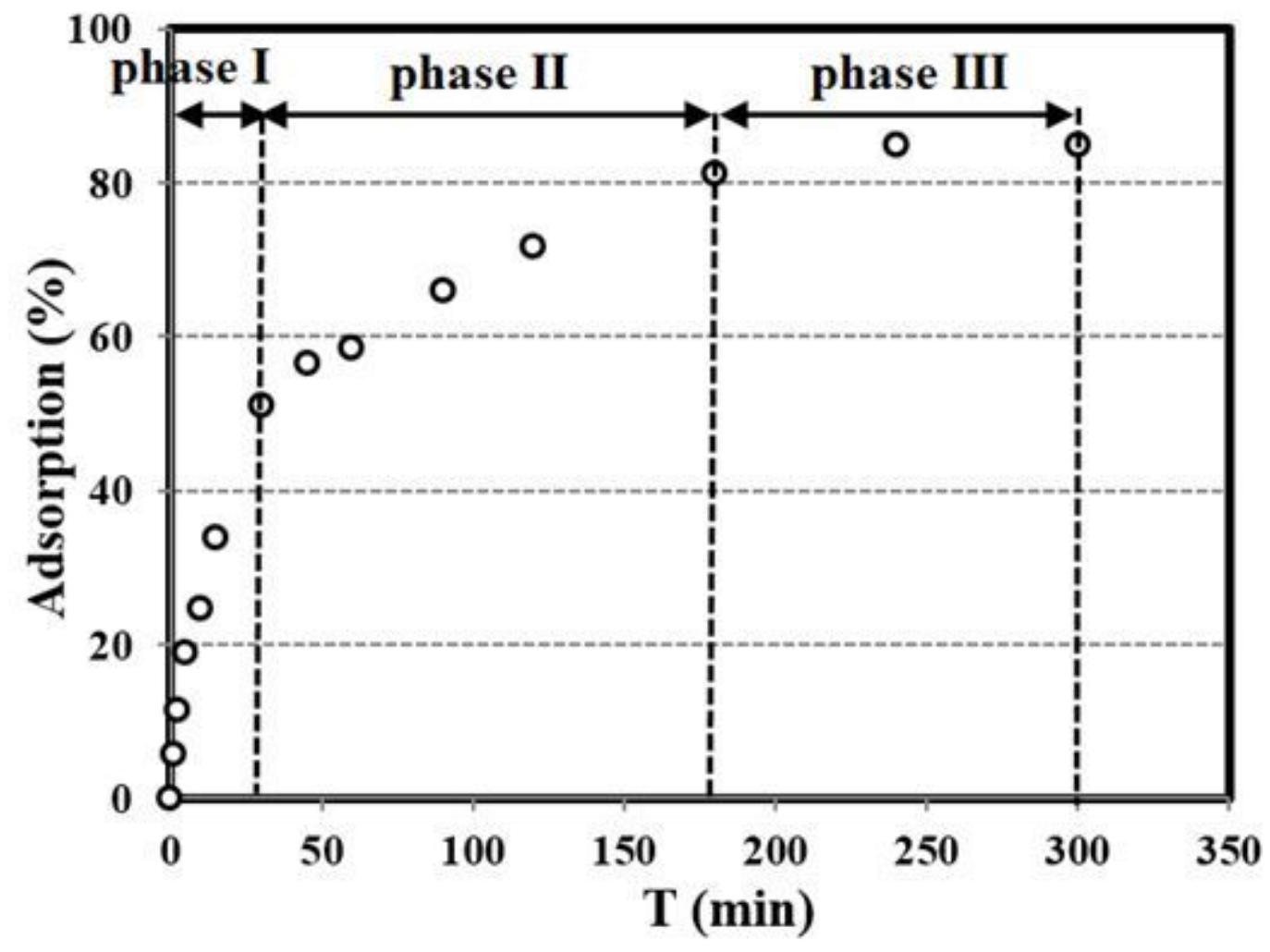

Figure 2

Different phases of the cadmium sorption. 

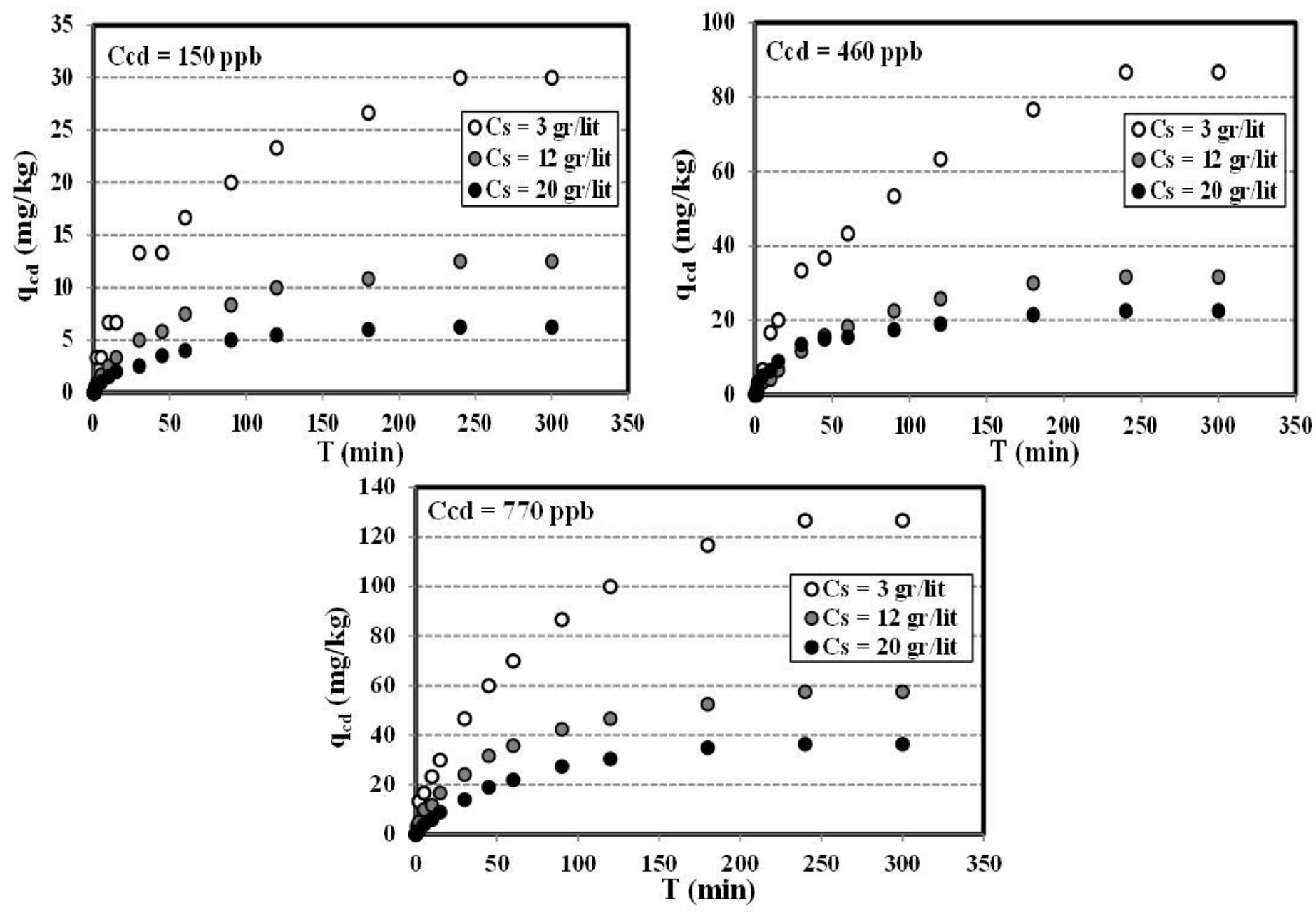

Figure 3

The effect of sediment concentration on the cadmium sorption

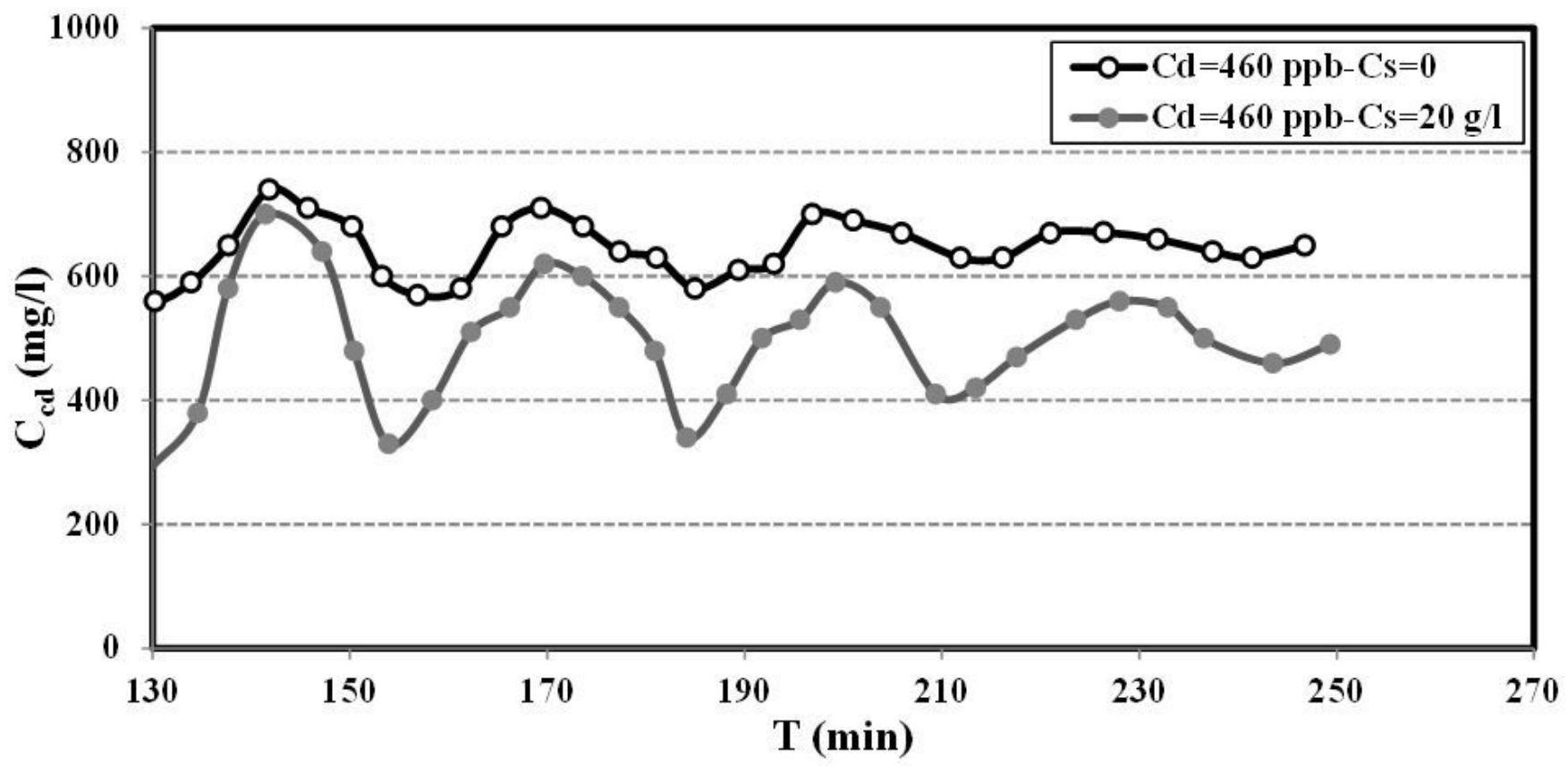


Figure 4

Time distribution of cadmium concentration ( $\mathrm{ppb} 460$ ) without and with sediment concentration of 20 g/lit.
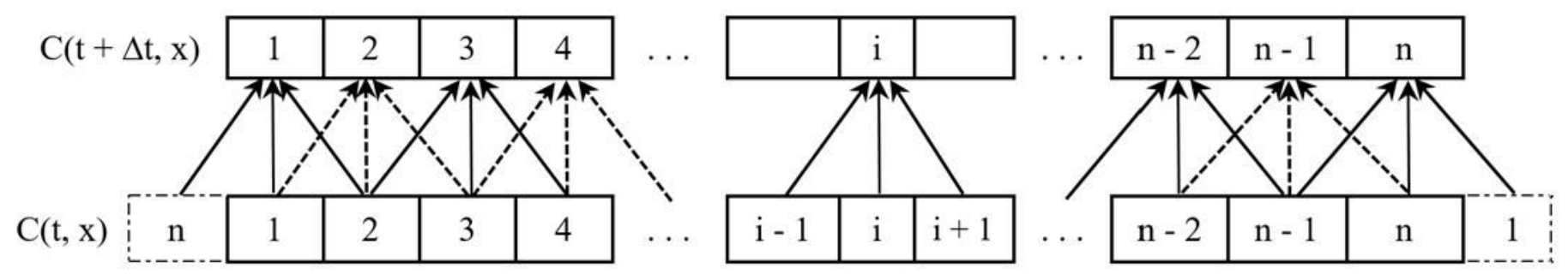

Figure 5

General Scheme for Numerical Modeling 

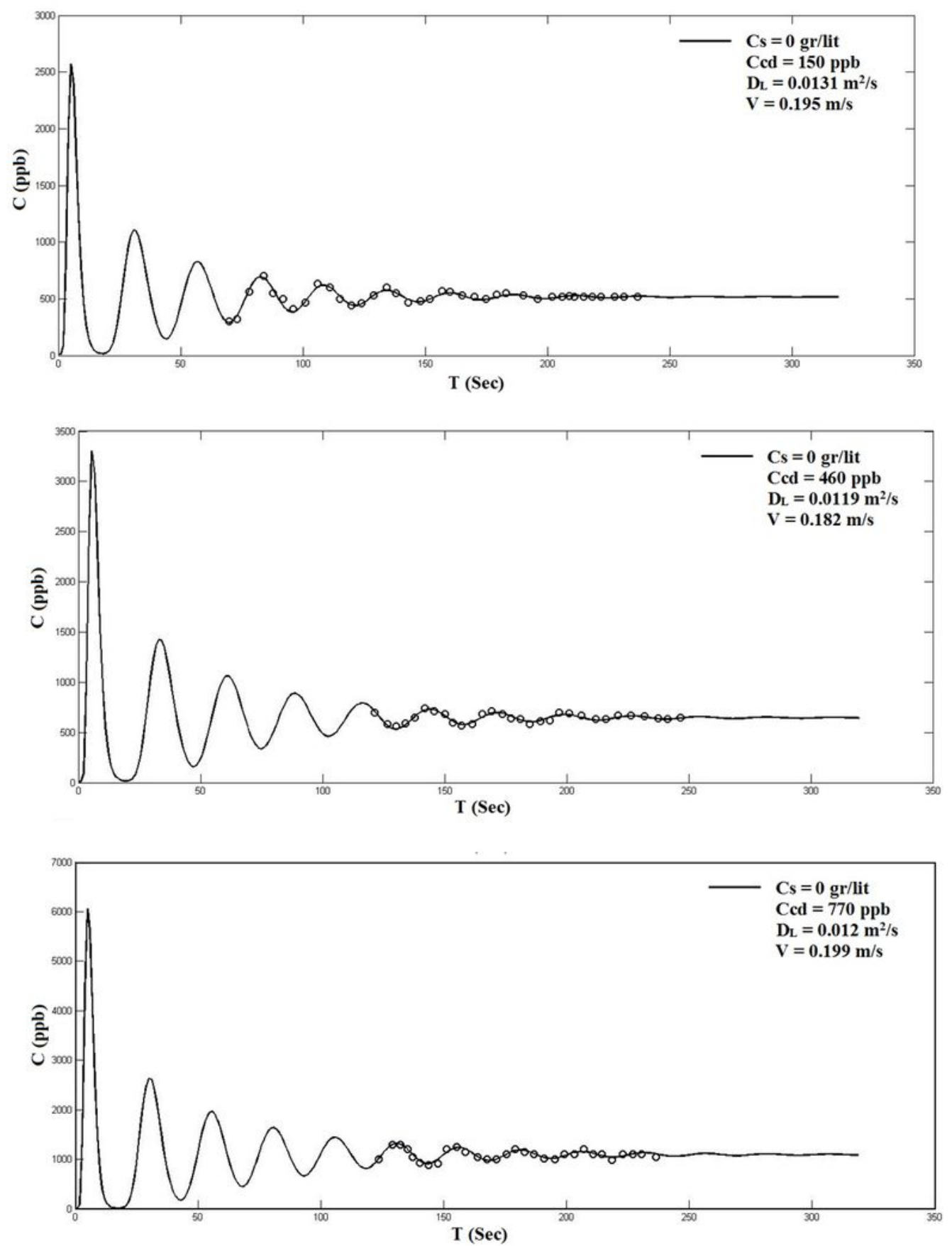

Figure 6

Time distribution of cadmium concentration; numerical results and experimental data. 

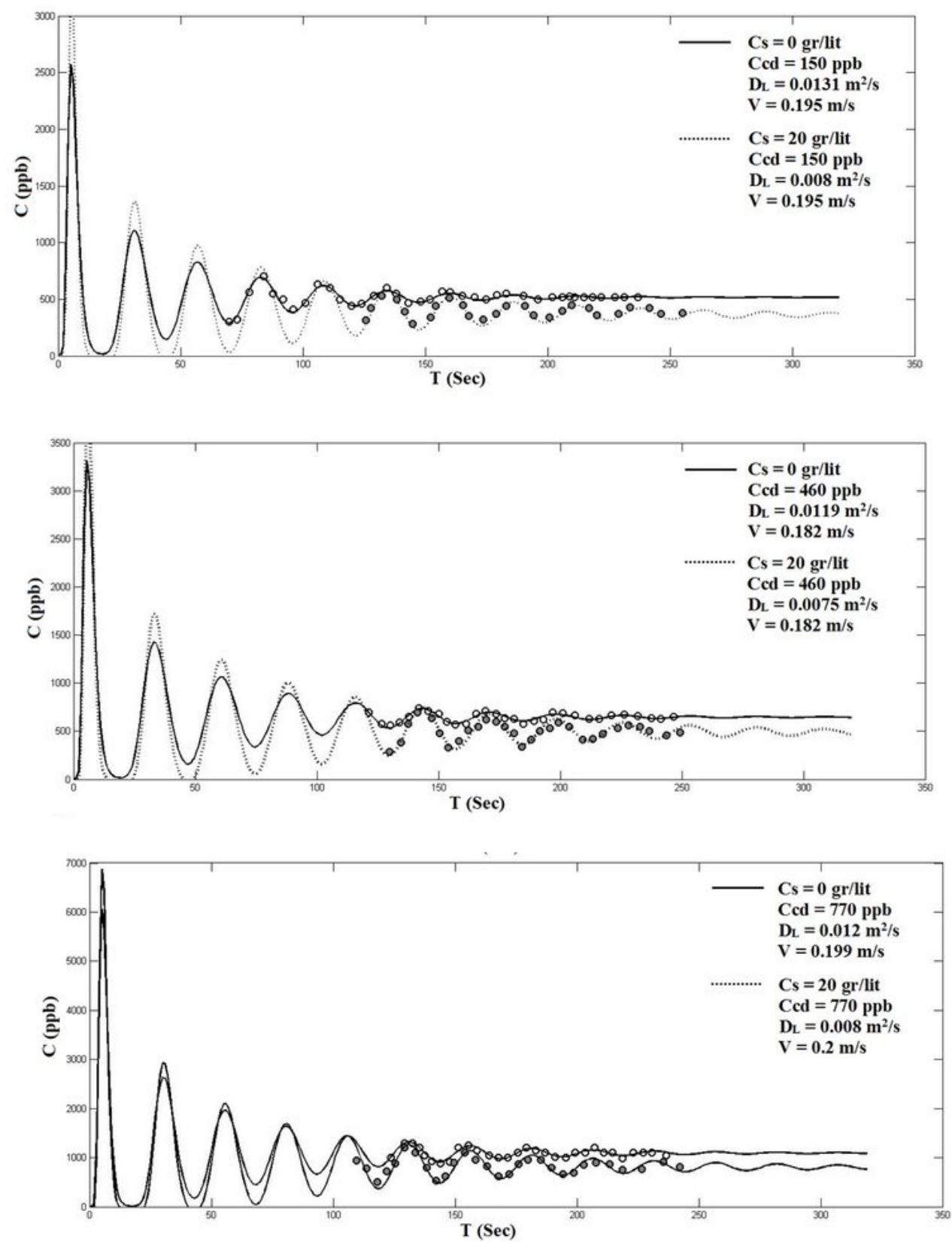

Figure 7

Time variations of cadmium concentrations with river bed sediments; numerical results and experimental data. 


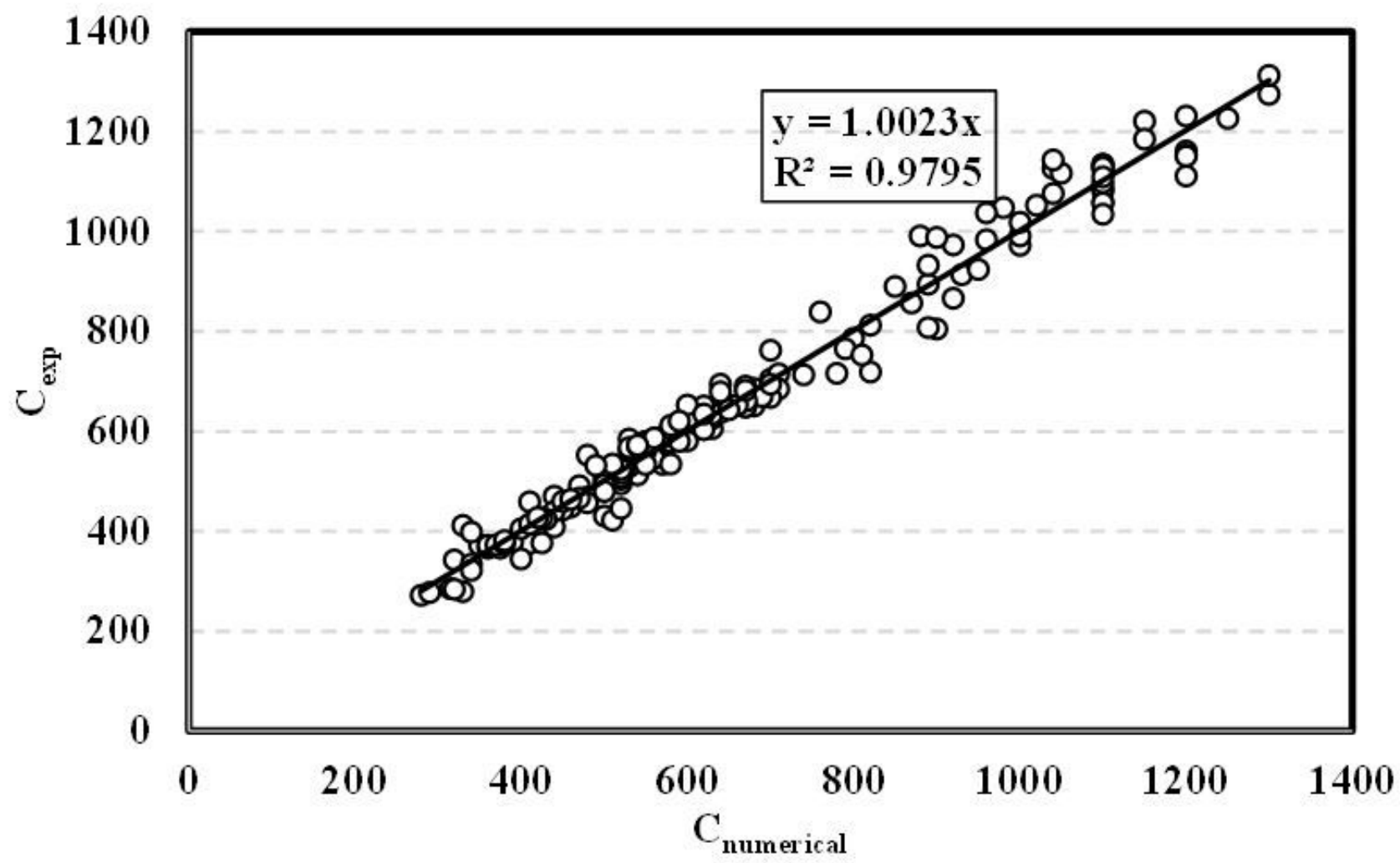

Figure 8

Measured data versus numerical modeling

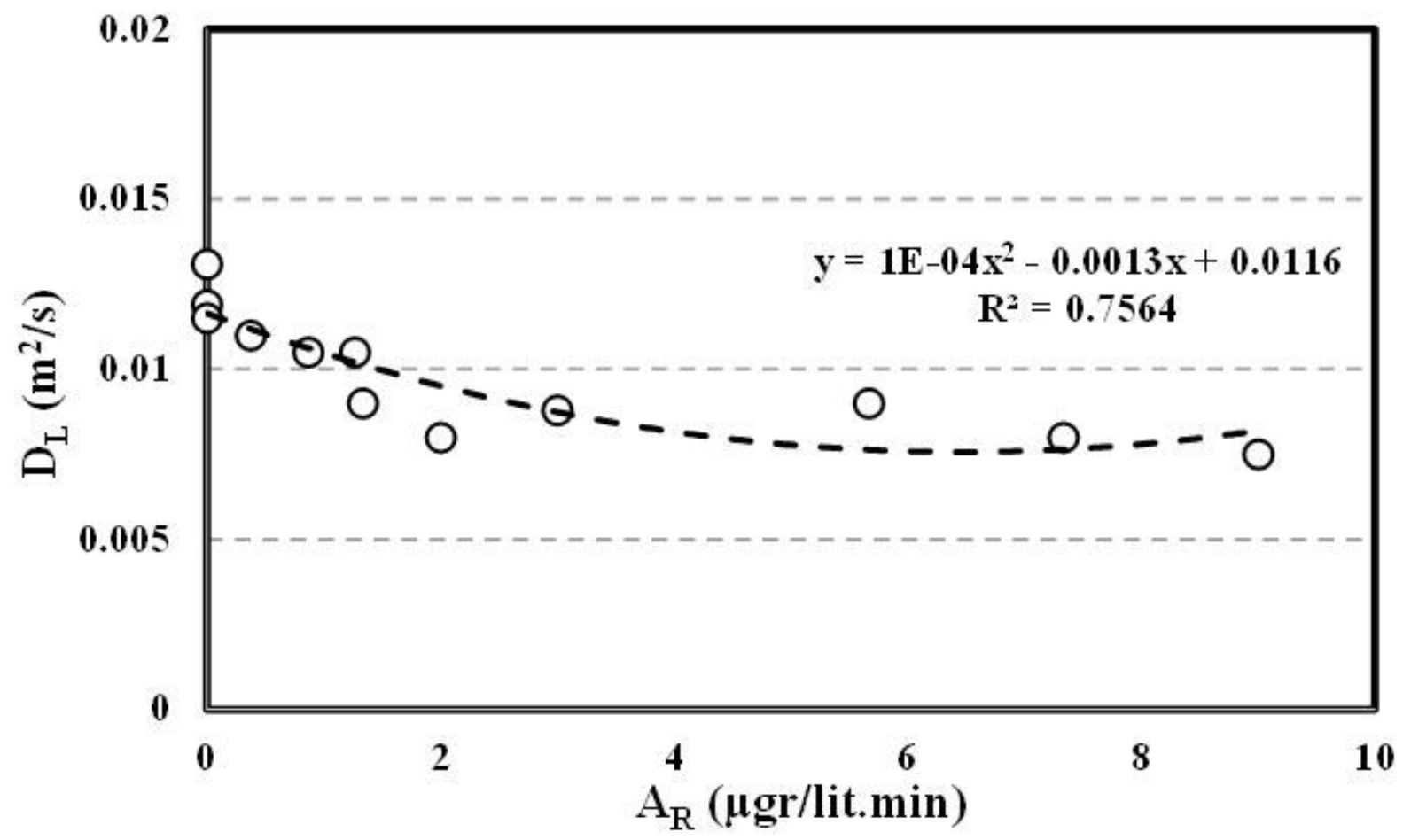

Figure 9 
Changes in longitudinal dispersion coefficient of cadmium versus sorption ratio. 